\title{
p53 overexpression is a prognosticator of poor outcome in esophageal cancer
}

\author{
NATHANIEL MELLING ${ }^{1 *}$, SONJA NORRENBROCK ${ }^{2 *}$, MARTINA KLUTH $^{2}$, RONALD SIMON $^{2}$, \\ CLAUDIA HUBE-MAGG ${ }^{2}$, STEFAN STEURER ${ }^{2}$, ANDREA HINSCH ${ }^{2}$, EIKE BURANDT $^{2}$, FRANK JACOBSEN $^{2}$, \\ WALDEMAR WILCZAK ${ }^{2}$, ALEXANDER QUAAS ${ }^{3}$, MAXIMILLIAN BOCKHORN ${ }^{1}$, \\ KATHARINA GRUPP $^{1}$, MICHAEL TACHEZY ${ }^{1}$, JAKOB IZBICKI ${ }^{1}$, GUIDO SAUTER $^{2}$ and FLORIAN GEBAUER ${ }^{4}$ \\ ${ }^{1}$ Department of General, Visceral and Thoracic Surgery; ${ }^{2}$ Institute for Pathology, \\ University Medical Center Hamburg-Eppendorf, D-20246 Hamburg; ${ }^{3}$ Institute for Pathology; \\ ${ }^{4}$ Department of Surgery, University Hospital Cologne, D-50937 Cologne, Germany
}

Received July 10, 2018; Accepted January 15, 2019

DOI: $10.3892 / \mathrm{ol} .2019 .10020$

\begin{abstract}
Immunohistochemistry studies on p53 inactivation in esophageal cancer are available with inconclusive results. Data on the combined effect of p53 protein accumulation and TP53 genomic deactivation in large scale studies for esophageal cancer are currently lacking. A tissue microarray with 691 esophageal cancer samples was analyzed by p53 immunohistochemistry and fluorescence in situ hybridization (FISH). Nuclear p53 accumulation was observed in $45.9 \%$ of patients with adenocarcinoma (AC) and in $40.0 \%$ in squamous cell carcinoma (SCC). Heterozygous TP53 deletions occurred in $40.9 \%$ in AC and in $19.4 \%$ in SCC. Homozygous deletions did not occur at all. High-level p53 immunostaining was associated with shortened overall survival in AC and SCC while TP53 deletions alone showed no correlation with survival. High-level p53 immunostaining in patients with $\mathrm{AC}$ was associated with advanced tumor $(\mathrm{P}=0.019)$ and Union for International Cancer Control stages $(\mathrm{P}=0.004)$, grading $(\mathrm{P}=0.027)$ and the resection margin status $(\mathrm{P}=0.006)$. Associations between $\mathrm{p} 53$ immunostaining and SCC were not found. TP53 deletions were found to be associated with advanced tumor stages $(\mathrm{P}=0.028)$ and the presence of lymph node metastasis $(\mathrm{P}=0.009)$ in SCC. In conclusion, strong p53 immunostaining, but not TP53 deletion alone, is associated with unfavorable outcomes and may therefore represent a clinically useful molecular marker in esophageal cancer.
\end{abstract}

Correspondence to: Mr. Nathaniel Melling, Department of General, Visceral and Thoracic Surgery, University Medical Center Hamburg-Eppendorf, Martinistr. 52, D-20246 Hamburg, Germany E-mail: n.melling@uke.de

*Contributed equally

Key words: p53 expression, outcome, esophageal cancer

\section{Introduction}

Esophageal cancer (EC) remains the sixth most common cause of cancer related death in the world despite recent progress in multimodal therapy concepts involving neoadjuvant therapy and standardized surgical approaches (1). EC is associated with high malignant potential for local invasion and early dissemination resulting in low overall-survival (OS) rates in patients even after curatively intended surgery (2).

There are two major histological types of EC that account for $>90 \%$ of all malignant neoplasms in the esophagus: squamous cell carcinoma and adenocarcinoma. The pathogenesis in adenocarcinoma is generally considered to be driven by epithelial metaplasia, often caused by acid reflux. In squamous cell carcinoma, malignant transformation is predominantly associated with alcohol intake and smoking (3). The incidence of the particular subtypes has changed in the past years with increase of adenocarcinoma and decrease of squamous cell carcinoma in Western countries, mainly due to life style changes (2). Due to the limited prognosis of the majority of patients, identification of new biomarkers predicting the individual prognosis and response to therapy are of imperative need for allocation of individualized therapy strategies.

The TP53 gene has been known as one of the most important tumor suppressor genes, located on human chromosome 17p13.1. p53 plays a major role in tumorigenesis as it controls cell growth, apoptosis and regulation of angiogenesis (4). Mutations in TP53 were found in $>50 \%$ of human cancers, which makes it one of the most mutated genes in tumors (5). In esophageal cancer, mutations have been described in frequencies between $40-70 \%$, depending on the underlying cell type (4,6-8). As shown for several tumor entities, inactivation of the TP53 tumor suppressor gene leads to the development of malignant cell clones and accelerates the carcinogenesis (9). Different mechanisms of functional p53 inactivation have been described including functionally relevant point mutations and gross chromosomal alterations, mostly driven by chromosome $17 \mathrm{p}$ deletions.

Previous studies reported inconclusive results on whether p53 accumulation has a functional impact on progression of 
EC (10-19). While some studies found associations between the p53 expression level and tumor progression or overall-survival, other studies were not able to confirm these findings. Data on TP53 deletion status is available from only one report including 40 patients suffering from esophageal squamous cell carcinoma (20).

To further elucidate the clinical relevance of TP53 mutations and p53 expression as prognostic biomarkers in esophageal cancer we took advantage of our preexisting tissue microarray (TMA) containing nearly 700 esophageal cancer specimens with attached clinical follow-up and clinico-pathological data.

Our findings demonstrate that strong p53 immunostaining is correlated with unfavorable prognosis in esophageal cancer, while homozygous TP53 deletions represent a catastrophic event leading to cell death.

\section{Materials and methods}

Patients. For this study, specimens from patients that had undergone tumor resection in curative intent between 1992 and 2014 at the University Medical Center, Hamburg-Eppendorf were included. Tissue samples from 691 patients were analyzed including 398 esophageal adenocarcinomas and 293 squamous cell carcinomas. All data including patient sex, tumor histology, size, lymph node metastasis and disease stage (UICC 7th edition) were obtained by reviewing a combination of clinical and pathological records, outpatient clinic medical records, epidemiological cancer surveillance data bases and by communication with the patients and their attending physicians. All resections were performed as en-bloc esophagectomies with radical two field lymph node dissection. Fifty patients underwent neoadjuvant therapy (AC $\mathrm{n}=30, \mathrm{SCC} \mathrm{n}=20$ ). Patients that died within 30 days due to postoperative complications were not considered for survival analysis.

Informed consent was not required due to the retrospective nature this study. Analysis of anonymized human tissue samples by the treating physician (including the pathologist) is permitted according to local laws (\$12a Hamburgisches Krankenhausgesetz). In addition, we obtained approval for manufacturing and analyzing tissue microarrays made from tissue samples from anonymized donors from our local review board, the Ethics Commission of the Ärztekammer Hamburg (no. WF049/09).

TMA construction. The TMA was constructed as previously described (21). In brief, tissue cores were obtained from formalin-fixed paraffin-embedded (FFPE) tissue blocks from patients with pathologically proven esophageal cancer. Representative areas of the tumor were selected based on hematoxylin-eosin staining. 691 tissue cylinders with a diameter of $0.6 \mathrm{~mm}$ were punched from the 'donor' tissue blocks using a custom-made semi-automatic robotic precision instrument and placed into one empty recipient paraffin block. The resulting TMA blocks were used to produce $4 \mu \mathrm{m}$ sections that were transferred to an adhesive-coated slide system (Instrumedics Inc., Hackensack, NJ, USA).

Immunohistochemistry. Freshly cut TMA sections were immunostained on one day and in one experiment. Slides were deparaffinized and exposed to heat-induced antigen retrieval for $5 \mathrm{~min}$ in an autoclave at $121^{\circ} \mathrm{C}$ in $\mathrm{pH} 7.8$ Tris-EDTA-Citrate buffer. Primary antibody specific for p53 (DO1, murine monoclonal $\mathrm{IgG}_{2 \mathrm{a}}$, Oncogene, Cambridge, MA; USA; dilution $1: 3,600$ ) was applied at $37^{\circ} \mathrm{C}$ for $60 \mathrm{~min}$. Bound antibody was then visualized using the EnVision Kit (Dako, Glostrup, Denmark) according to the manufacturer's directions.

Colon cancers with known p53 alterations served as positive controls and normal prostate tissue as negative controls on each TMA section. Nuclear p53 staining intensity was scored in a four-step scale $(0,1+, 2+, 3+$ staining intensity) and the percentage of stained nuclei was estimated. A final immunohistochemistry (IHC) result was assigned to each tumor as described in earlier studies from our group (22). Negative: No staining at all or $1+/ 2+$ staining in $<10 \%$ of tumor cells, low: $1+$ staining in $\geq 10 \%$ or $2+$ staining in $\geq 10 \%$ but $\leq 70 \%$ of tumor cells or $3+$ staining in $\leq 10 \%$ of tumor cells, high: $2+$ staining in $>70 \%$ of tumor cells or $3+$ staining in $>10 \%$ of tumor cells. For calculation of results low and high staining intensities were summed up as positive.

FISH. FISH was used to identify genomic TP53 deletions and translocations. A dual color FISH probe was constructed from a spectrum green labeled BAC clone (BACs RP11-89D11, RP11-404G1; Source Bioscience, Nottingham, UK) and a commercial spectrum orange labeled centromere 17 (CEP17) reference probe (no. 06J36-06; Abbott Molecular, Wiesbaden, Germany). Freshly cut $4 \mu \mathrm{m}$ TMA sections were used for dual color FISH. Before hybridization, sections were deparaffinized and proteolytically pretreated with a commercial kit (paraffin pretreatment reagent kit; Abbott Molecular), followed by dehydration in 70,80 and $96 \%$ ethanol, air drying and denaturation for $10 \mathrm{~min}$ at $72^{\circ} \mathrm{C}$ in $70 \%$ formamide- 23 saline-sodium citrate (SSC) solution. Hybridization was done overnight at $37^{\circ} \mathrm{C}$ in a humidified chamber, slides were washed and counterstained with $0.2 \mathrm{mmol} / 1$ 40-6-diamidino-2-phenylindole in an antifade solution.

FISH Scoring. Each TMA spot was carefully evaluated and the predominant TP53 signal counts were recorded for each FISH probe. Tissue samples with missing tumor tissue as determined by corresponding $\mathrm{H} \& \mathrm{E}$ slides were not considered for analysis. In addition, tumor spots were excluded from analysis if there was evidence for insufficient hybridization such as lack of TP53 signals in both tumor and peritumoral non-malignant tissue. Deletion of TP53 was defined as presence of fewer TP53 signals than centromere 17 probe signals (heterozygous deletion) or complete absence of TP53 signals but presence of at least one centromere 17 probe signal (homozygous deletion) in $\geq 60 \%$ of tumor nuclei. The aforementioned cut-off level was chosen because a good correlation between FISH and array genomic hybridization was already shown by our group for PTEN and p53 in prostate cancer $(22,23)$.

Statistical analysis. SPSS Statistics for Mac (version 17; SPSS, Inc., Chicago, IL, USA) was used for statistical analysis. Interdependence between immunostaining and FISH results as well as clinical data was calculated using the Chi-squared and Fisher's exact tests and displayed by cross-tables. Group differences were examined using the t-test. Survival curves 

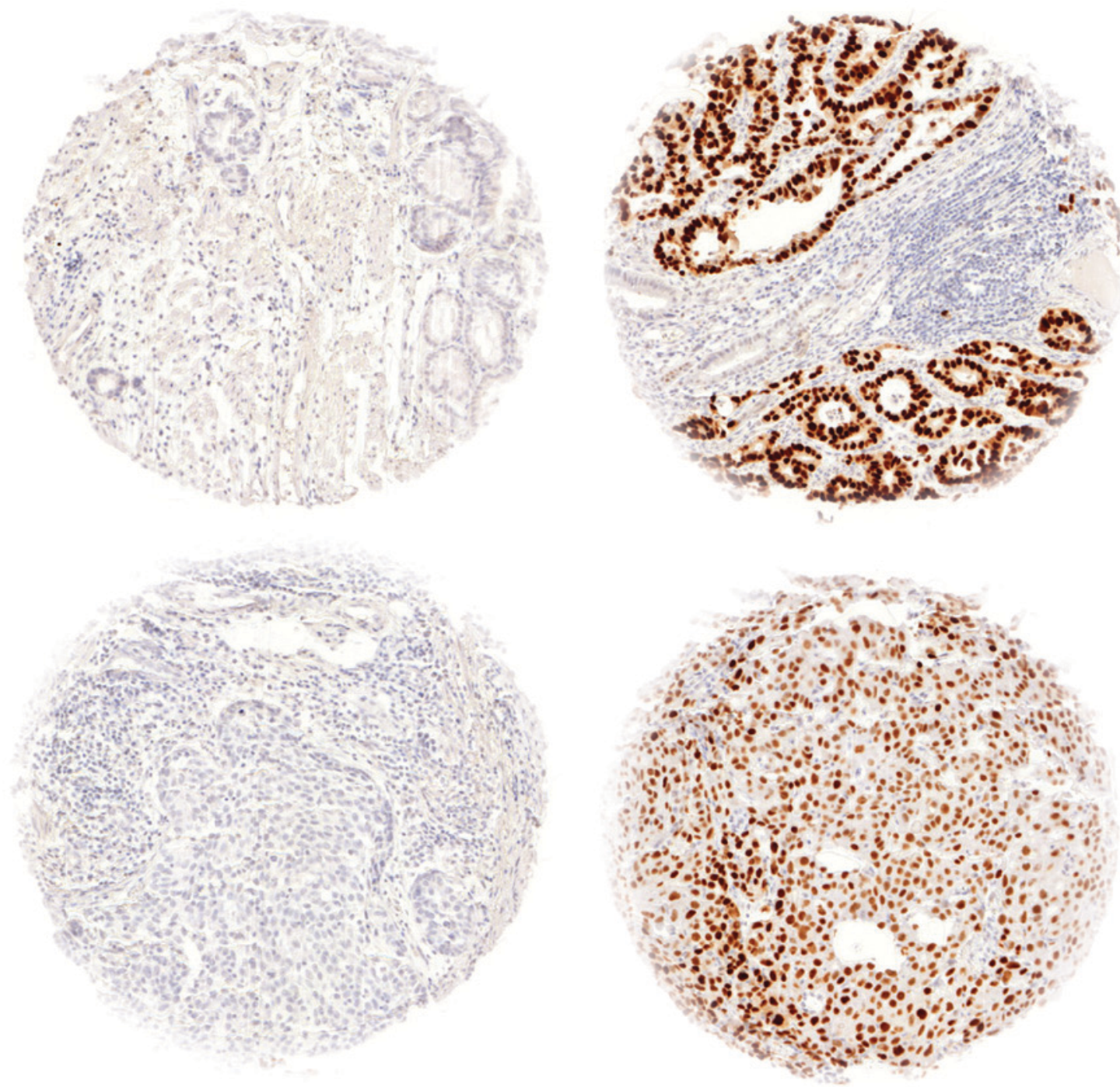

Figure 1. Representative images of negative and positive p53 immunostaining in adenocarcinoma and squamous cell carcinoma.

were plotted using the Kaplan-Meier method and analyzed using the log-rank test. Univariate and multi-variate analyses were performed for prognostic factors of recurrence-free and overall survival using the Cox regression model. All tests were two-sided. $\mathrm{P}<0.05$ was considered to indicate a statistically significant difference.

\section{Results}

p53 IHC. p53 immunostaining was interpretable in 574 (83.2\%) of 691 samples, in total 314 esophageal adenocarcinomas (AC) and 260 squamous cell carcinomas (SCC) were evaluable. Reasons for non-informative cases included lack of tissue samples or absence of unequivocal cancer tissue in the TMA spot. p53 positivity was seen in 104 SCC (40.0\%) and in 144 AC of the esophagus (45.9\%). Representative images of p53 immunostaining in $\mathrm{AC}$ and $\mathrm{SCC}$ are given in Fig. 1. p53 positivity was associated with tumor stage $(\mathrm{P}=0.019)$, UICC stage $(\mathrm{P}=0.004)$, grading $(\mathrm{P}=0.027)$ and surgical resection margin status $(\mathrm{P}=0.006)$ in esophageal AC (Table I), while no associations between clinico-pathological data and p53 immunostaining in squamous cell carcinoma were revealed (Table II).
TP53 FISH analysis. FISH was interpretable for TP53 deletions in $269(67.6 \%)$ samples in esophageal adenocarcinoma and 237 (80.9\%) samples in squamous cell carcinoma. Non-informative cases were caused by inefficient hybridization, missing tissue spots or absence of representative tumor tissue on the TMA spot. Heterozygous TP53 deletions were detectable in 110 samples (40.9\%) in EC and 46 samples (19.4\%) in SCC. TP53 deletions were associated with age $(\mathrm{P}=0.031)$ and surgical resection margin $(\mathrm{P}=0.029)$ in adenocarcinoma (Table I). For squamous cell carcinoma, associations were detected between heterozygous TP53 deletions and tumor stage $(\mathrm{P}=0.028)$ and presence of lymph node metastasis $(\mathrm{P}=0.009)$ (Table II). Not one single TMA spot revealed cells with homozygous TP53 deletions.

Combined effect of p53 immunostaining and TP53 deletions. Data on both p53 immunostaining and TP53 FISH were available from 244 adenocarcinomas and 223 squamous cell carcinomas. A correlation between high p53 immunostaining and TP53 deletion could not be revealed for AC $(\mathrm{P}=0.643)$ while in $\mathrm{SCC}$ an association $(\mathrm{P}=0.044)$ was seen. In adenocarcinoma, 54 (21.8\%) tumors showed heterozygous TP53 
Table I. Association between p53 immunostaining and TP53 FISH with clinicopathological parameters in adenocarcinoma.

\begin{tabular}{|c|c|c|c|c|c|c|c|c|}
\hline \multirow[b]{2}{*}{ Parameter } & \multicolumn{4}{|c|}{ p53 IHC result } & \multicolumn{4}{|c|}{ TP53 FISH result } \\
\hline & $\begin{array}{l}\text { Evaluable } \\
\text { cases (n) }\end{array}$ & Negative (\%) & Positive (\%) & P-value & $\begin{array}{c}\text { Evaluable } \\
\text { cases (n) }\end{array}$ & $\begin{array}{l}\text { no del } \\
(\%)\end{array}$ & $\begin{array}{c}\text { het del } \\
(\%)\end{array}$ & P-value \\
\hline All tumors & 314 & 54.1 & 45.9 & & 269 & 59.1 & 40.9 & \\
\hline Age, years & & & & 0.645 & & & & 0.031 \\
\hline$\leq 65$ & 107 & 52.3 & 47.7 & & 91 & 89.2 & 10.8 & \\
\hline$>65$ & 207 & 55.1 & 44.3 & & 178 & 69.9 & 30.1 & \\
\hline Sex & & & & 0.186 & & & & 0.074 \\
\hline Male & 262 & 52.7 & 47.3 & & 226 & 63.4 & 36.6 & \\
\hline Female & 51 & 62.7 & 37.3 & & 42 & 95.9 & 4.5 & \\
\hline Tumor stage & & & & 0.019 & & & & 0.195 \\
\hline pT1 & 61 & 70.5 & 29.5 & & 40 & 92.2 & 7.8 & \\
\hline pT2 & 33 & 60.6 & 39.4 & & 26 & 95.9 & 4.1 & \\
\hline pT3 & 96 & 49.0 & 51.0 & & 156 & 72.8 & 27.2 & \\
\hline pT4 & 22 & 45.4 & 54.6 & & 21 & 98.1 & 1.9 & \\
\hline Lymph node metastasis & & & & 0.069 & & & & 0.923 \\
\hline pNO & 96 & 64.6 & 35.4 & & 79 & 88.4 & 11.6 & \\
\hline pN1 & 51 & 53.0 & 47.0 & & 50 & 92.5 & 7.5 & \\
\hline $\mathrm{pN} 2$ & 81 & 51.9 & 48.1 & & 65 & 89.2 & 10.8 & \\
\hline $\mathrm{pN} 3$ & 84 & 45.2 & 54.8 & & 74 & 88.8 & 11.2 & \\
\hline Distant metastasis & & & & 0.475 & & & & 0.974 \\
\hline M0 & 277 & 54.9 & 45.1 & & 237 & 63.9 & 36.1 & \\
\hline M1 & 37 & 48.6 & 51.4 & & 32 & 95.2 & 4.8 & \\
\hline UICC stage & & & & 0.004 & & & & 0.977 \\
\hline $\mathrm{I}$ & 62 & 72.6 & 27.4 & & 52 & 92.5 & 7.5 & \\
\hline II & 41 & 61.0 & 39.0 & & 33 & 95.1 & 4.9 & \\
\hline III & 173 & 48.0 & 52.0 & & 151 & 76.3 & 23.7 & \\
\hline IV & 34 & 44.1 & 55.9 & & 30 & 95.5 & 4.5 & \\
\hline Grading & & & & 0.027 & & & & 0.922 \\
\hline G1 & 15 & 86.7 & 13.3 & & 12 & 98.5 & 1.5 & \\
\hline $\mathrm{G} 2$ & 113 & 54.9 & 45.1 & & 98 & 84.2 & 15.8 & \\
\hline G3 & 175 & 50.9 & 49.1 & & 152 & 76.2 & 23.8 & \\
\hline G4 & 6 & 83.3 & 16.7 & & 3 & 99.6 & 0.4 & \\
\hline Surgical resection margin & & & & 0.006 & & & & 0.029 \\
\hline R0 & 228 & 59.2 & 40.8 & & 174 & 72.7 & 27.3 & \\
\hline R1 & 78 & 38.5 & 61.5 & & 63 & 86.4 & 13.6 & \\
\hline $\mathrm{R} 2$ & 3 & 66.7 & 33.3 & & 3 & 99.6 & 0.4 & \\
\hline
\end{tabular}

FISH, fluorescence in situ hybridization; IHC, immunohistochemistry; UICC, Union for International Cancer Control; het del, heterozygous deletion; no del, no deletion.

deletion accompanied by high p53 expression which was also displayed by 25 SCC $(11.2 \%)$. However, this finding was merely associated with resection margin status $(\mathrm{P}=0.013)$ in esophageal AC.

Survival analysis. In total, 283 patients with adenocarcinoma and 231 with squamous cell carcinoma were available for survival analysis. High-level p53 immunostaining was linked to shortened overall-survival (OS) in both esophageal AC and
SCC as analyzed by Kaplan-Meier $(\mathrm{P}=0.021$ and $\mathrm{P}=0.013$, respectively; Fig. 2A and D). TP53 deletions were not associated with $\mathrm{OS}$ irrespective of the histological type $(\mathrm{P}=0.973$ (AC) and $\mathrm{P}=0.099$ (SCC); Fig. 2B and E). Combination of p53 expression and TP53 deletion status did not improve the prognostic power compared to p53 IHC alone (Fig. 2C and F).

Multivariate analysis. For both histological types, UICC stage and a complete surgical resection (R0) proved to be independent 
Table II. Association of p53 immunostaining and TP53 fluorescence in situ hybridization with clinicopathological parameters in squamous cell carcinoma.

\begin{tabular}{|c|c|c|c|c|c|c|c|c|}
\hline \multirow[b]{2}{*}{ Parameter } & \multicolumn{4}{|c|}{ p53 IHC result } & \multicolumn{4}{|c|}{ TP53 FISH result } \\
\hline & $\begin{array}{c}\text { Evaluable } \\
\text { cases (n) }\end{array}$ & Negative $(\%)$ & Positive (\%) & P-value & $\begin{array}{l}\text { Evaluable } \\
\text { cases (n) }\end{array}$ & $\begin{array}{c}\text { no del } \\
(\%)\end{array}$ & $\begin{array}{l}\text { het del } \\
(\%)\end{array}$ & P-value \\
\hline All tumors & 260 & 60.0 & 40.0 & & 237 & 80.6 & 19.4 & \\
\hline Age, years & & & & 0.678 & & & & 0.11 \\
\hline$<65$ & 101 & 58.4 & 41.6 & & 94 & 90.3 & 9.7 & \\
\hline$>65$ & 159 & 61.0 & 39.0 & & 143 & 90.3 & 9.7 & \\
\hline Sex & & & & 0.568 & & & & 0.945 \\
\hline Male & 190 & 61.1 & 38.9 & & 171 & 86.1 & 13.9 & \\
\hline Female & 70 & 57.1 & 42.9 & & 66 & 94.5 & 5.5 & \\
\hline Tumor stage & & & & 0.694 & & & & 0.028 \\
\hline pT1 & 43 & 67.4 & 32.6 & & 42 & 97.9 & 2.1 & \\
\hline pT2 & 55 & 56.4 & 43.6 & & 46 & 98.3 & 1.7 & \\
\hline pT3 & 144 & 59.7 & 40.3 & & 134 & 85.2 & 14.8 & \\
\hline pT4 & 18 & 55.6 & 44.4 & & 15 & 99.2 & 0.8 & \\
\hline Lymph node metastasis & & & & 0.276 & & & & 0.009 \\
\hline pNO & 123 & 53.7 & 46.3 & & 115 & 92.4 & 7.6 & \\
\hline $\mathrm{pN} 1$ & 58 & 63.8 & 36.2 & & 53 & 95.8 & 4.2 & \\
\hline $\mathrm{pN} 2$ & 52 & 67.3 & 32.7 & & 49 & 95.8 & 4.2 & \\
\hline $\mathrm{pN} 3$ & 26 & 65.4 & 34.6 & & 20 & 96.6 & 3.4 & \\
\hline Distant metastasis & & & & 0.873 & & & & 0.62 \\
\hline M0 & 211 & 59.7 & 40.3 & & 195 & 83.5 & 16.5 & \\
\hline M1 & 49 & 61.2 & 38.8 & & 42 & 97.0 & 3.0 & \\
\hline UICC stage & & & & 0.903 & & & & 0.074 \\
\hline I & 60 & 13.1 & 10.0 & & 6 & 97.5 & 2.5 & \\
\hline II & 60 & 14.6 & 8.5 & & 9 & 96.2 & 3.8 & \\
\hline III & 91 & 20.8 & 14.2 & & 23 & 90.3 & 9.7 & \\
\hline IV & 49 & 11.2 & 7.3 & & 8 & 96.6 & 3.4 & \\
\hline Grading & & & & 0.63 & & & & 0.81 \\
\hline G1 & 3 & 0.4 & 0.8 & & 4 & 99.6 & 0.4 & \\
\hline G2 & 163 & 38.1 & 24.6 & & 151 & 88.6 & 11.4 & \\
\hline G3 & 93 & 21.5 & 14.2 & & 81 & 92.8 & 7.2 & \\
\hline Surgical resection margin & & & & 0.84 & & & & 0.54 \\
\hline R0 & 192 & 43.8 & 30.0 & & 179 & 86.4 & 13.6 & \\
\hline $\mathrm{R} 1$ & 52 & 12.7 & 7.3 & & 45 & 95.3 & 4.7 & \\
\hline $\mathrm{R} 2$ & 14 & 3.1 & 2.3 & & 12 & 98.7 & 1.3 & \\
\hline
\end{tabular}

FISH, fluorescence in situ hybridization; IHC, immunohistochemistry; UICC, Union for International Cancer Control; het del, heterozygous deletion; no del, no deletion.

prognostic markers as analyzed by multivariate cox-regression model. Furthermore, strong p53 immunostaining was also independently associated with OS in SCC (Table III).

\section{Discussion}

Our study shows that p53 overexpression is linked to shortened overall survival in patients suffering from EC. To our knowledge, this is the study includes the largest number of cases for
EC and SCC with corresponding survival data. Furthermore, we correlated p53 IHC and TP53 FISH analysis. As follows in the discussion, previous studies either present inconclusive results or include only few patients.

In our analysis p53 alterations are present in 40-45\% of esophageal cancer, irrespective of the underlying histological type. Genome studies conducted either with array comparative genome hybridization $(\mathrm{CGH})$ or whole genome sequencing repeatedly revealed TP53 mutations as the most 
Table III. Multivariate analysis of p53 immunostaining in esophageal cancer.

\begin{tabular}{|c|c|c|c|c|c|c|c|c|}
\hline \multirow[b]{3}{*}{ Parameter } & \multicolumn{4}{|c|}{ Adenocarcinoma } & \multicolumn{4}{|c|}{ Squamous cell carcinoma } \\
\hline & \multirow[b]{2}{*}{ HR } & \multicolumn{2}{|c|}{$\begin{array}{l}95 \% \text { confidence } \\
\text { interval }\end{array}$} & \multirow[b]{2}{*}{ P-value } & \multirow[b]{2}{*}{ HR } & \multicolumn{2}{|c|}{$\begin{array}{l}95 \% \text { confidence } \\
\text { interval }\end{array}$} & \multirow[b]{2}{*}{ P-value } \\
\hline & & Lower & Upper & & & Lower & Upper & \\
\hline Sex (male/female) & 0.741 & 0.462 & 1.187 & 0.212 & 0.815 & 0.562 & 1.184 & 0.284 \\
\hline Age group $(<65 />65$ years $)$ & 1.414 & 0.965 & 2.072 & 0.076 & 0.920 & 0.663 & 1.277 & 0.620 \\
\hline UICC Stage & 2.232 & 1.626 & 3.065 & $<0.001$ & 1.288 & 1.019 & 1.629 & 0.034 \\
\hline Distant metastasis & 1.095 & 0.581 & 2.063 & 0.780 & 1.001 & 0.579 & 1.730 & 0.998 \\
\hline Surgical resection margin & 1.677 & 1.152 & 2.440 & 0.007 & 1.396 & 1.061 & 1.836 & 0.017 \\
\hline Grading & 1.219 & 0.874 & 1.700 & 0.243 & 1.131 & 0.829 & 1.543 & 0.438 \\
\hline p53 immunostaining & 1.186 & 0.829 & 1.698 & 0.351 & 1.459 & 1.054 & 2.022 & 0.023 \\
\hline TP53 FISH & 0.853 & 0.593 & 1.227 & 0.391 & 1.095 & 0.745 & 1.610 & 0.643 \\
\hline
\end{tabular}

FISH, fluorescence in situ hybridization; UICC, Union for International Cancer Control; HR, hazard ratio.

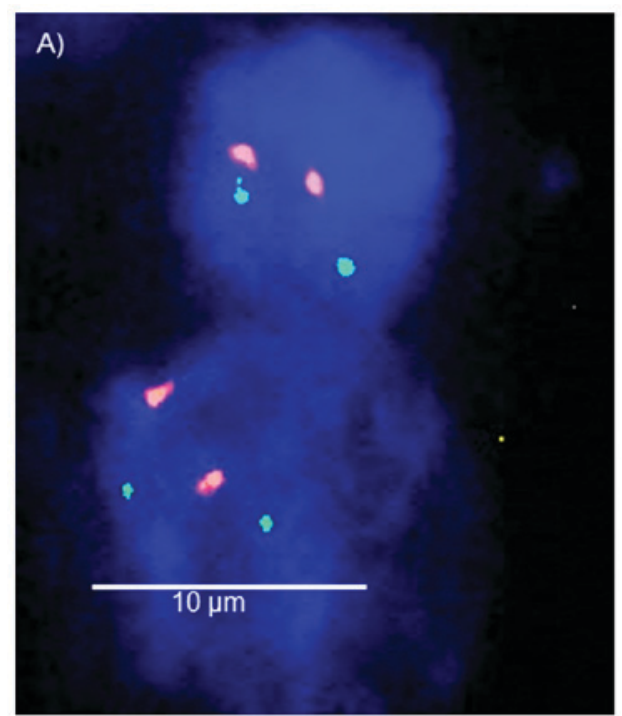

Normal TP53 copy number

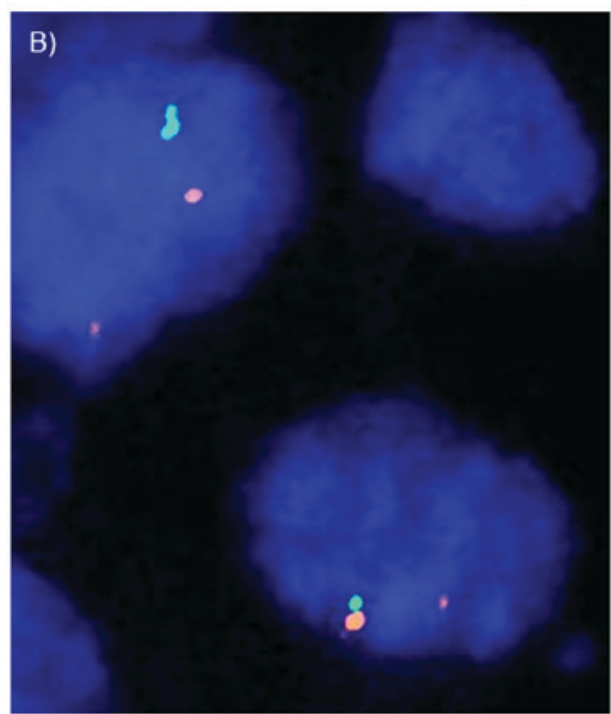

Heterozygous TP53 deletion

\section{green signal: TP53; orange signal: centromere 17}

Figure 2. Representative images of fluorescence in situ hybridization results using the TP53 deletion probe. (A) Normal TP53 copy numbers are indicated by two green TP53 signals and two orange centromere 17 signals. (B) Heterozygous TP53 deletion is indicated by the lack of one green TP53 signal. Scale bars, $10 \mu \mathrm{m}$.

common gene mutation in EC with reported mutation rates between $40-70 \%(4,7,24)$. The variance of the reported mutation frequencies is in concordance to immunohistochemical confirmation studies for SSC and the results revealed from our study $(19,25-28)$. In contrast, data from large patient cohorts concerning p53 expression in esophageal adenocarcinoma are hardly available. A recent review article by Chen and colleagues analyzed biomarkers in esophageal cancer and found only 2 studies focusing on p53 expression in esophageal adenocarcinoma with 97 patients included in the meta-analysis (14). These studies also showed p53 protein alterations in $40-65 \%$, although the case load is too small to draw general conclusions. Our group has previously shown that the applied IHC protocols, for prostate cancer, reveal high concordance of IHC data with sequencing results, arguing for a strong validity of our IHC protocol (22).

p53 is physiologically expressed by numerous cell types and plays a major role in cell cycle control. It is considered one of the most important tumor suppressor genes (9). p53 mutations have been found in multiple cancers with large variances in the mutation frequency, depending on the observed tumor entity (29).

In our study heterozygous TP53 deletions were found in $41 \%$ of AC and $19 \%$ of SCC. Only little data on TP53 gene deletions have yet been reported. Recently, a study on 40 patients suffering from esophageal squamous cell carcinoma revealed heterozygous deletion of TP53 in 22 patients 
(55\%). A correlation with clinical data could not be established in this study (20). The deletion rate is somewhat higher than it is in our data, which is partially caused by our stringent criteria for defining TP53 deletions. These were applied to avoid false deletion calling due to truncation of the nuclei during tissue sectioning. Most samples with TP53 deletion had $>80 \%$ cells with fewer TP53 fluorescence signals than centromere 17 signals. In contrast to other studies, we did not use automated systems for detection of particular gene deletions which is another possibility for deviating deletion rates compared to previous published reports (20). As already shown in prostate cancer on a TMA with $>11,000$ patient samples, $100 \%$ concordance between array-CGH detected deletions and FISH could be achieved for PTEN and TP53 deletions using these criteria $(22,23,30)$. Therefore, differences in the deletion rate are explained by different protocols calling more deletions as present within one patient sample. The deletion rate of $19 \%$ supports the assumption that TP53 deletions have only minor significance as a pathway for p53 inactivation in esophageal SCC. In line with the results revealed by our study, the impact of p53 mutations is of higher importance with respect to tumor progression than the heterozygous gene deletion of chromosome 17p13. These findings also match a Northern blot analysis on expression of the p53 gene in esophageal tumorigenesis. RNA was extracted from tumor, Barrett's epithelium, and histologically normal esophageal mucosa. p53 was found to be overexpressed in cancerous or metaplastic tissue in comparison to normal tissue. Thus, the authors concluded that p53 is implicated in the progression of Barrett's epithelium to invasive cancer (31).

By analyzing p53 immunostaining and TP53 deletions, we were able to correlate p53 IHC and TP53 deletion status with corresponding clinical data of our patient cohort. Patients with p53 overexpression in IHC presented with shortened OS and unfavorable clinic-pathological data, meaning that p53 mutations must have an influence on tumor biology. This effect is also paralleled by a significant correlation between advanced tumor stages and high p53 expression levels in AC (Table I: Tumor stage $(\mathrm{P}=0.019)$, UICC stage $(\mathrm{P}=0.004)$, grading $(\mathrm{P}=0.027)$ and surgical resection margin status $(\mathrm{P}=0.006))$. Furthermore, the multivariate analysis of p53 immunostaining in a setting with various established prognostic factors for esophageal cancer, such as UICC stage, distant metastasis, resection margin and grading revealed that p53 accumulation is an independent prognostic marker in SCC. In contrast, in our analysis, heterozygous TP53 deletions do not affect the OS, neither in AC nor in SCC. These results confirm the findings of former studies in EC and other tumor entities that mono-allelic protein expression is sufficient for regular cell cycle control mediated by p53 (29). Our data show, that mono-allelic TP53 deletion cannot be considered a major driver for tumor progression in esophageal cancer while there is no mutation in the remaining TP53 allele.

Since the poor outcome of patients with strong p53 immunostaining was independent of the TP53 deletion status, it is tempting to speculate that these cancers may at least carry dominant negative mutations with complete inactivation of wild-type $\mathrm{p} 53$ protein through complex formation with mutant p53 protein. This mechanism is known to lead to massive nuclear accumulation of inactive $\mathrm{p} 53$ complexes composed of mutated and non-mutated p53 protein (29).
While IHC reveals both mutated and non-mutated p53, cells with accumulation of inactive p53 complexes are the ones that will predominantly show strong staining. Thus, strong p53 immunostaining in our samples indicates an accumulation of unfunctional $\mathrm{p} 53$.

Alterations of $\mathrm{p} 53$ have been found in virtually every region of the protein but only a handful of the most frequently occurring mutations haven been studied in depth for their contribution to cancer progression (32). In EC, the majority of patients present with TP53 exon single nucleotide mutations (approximately 70\%) while frameshift mutations are much less frequent. Only $15 \%$ of cases have been reported to have insertions or deletions as found by genome wide sequencing and PCR exon analysis $(6,32)$. Numerous in vitro and in vivo studies confirmed the ability of mutant p53 to drive enhanced cancer invasion and motility, with evidence that mutant p53 can enhance signaling through receptors such as transforming growth factor $\beta$ (TGF $\beta$ ) or epidermal growth factor receptor (EGFR). Additionally, although mutated p53 has generally lost the ability to bind p53 DNA binding regions in target gene promoters, various p53 mutants can bind directly to DNA with some degree of selectivity and may thereby control the transcription of certain genes $(33,34)$. Furthermore, there is increasing evidence that mutated p53 has an inhibitory effect on transcription factors, such as TAp63, which is of regulative importance for numerous miRNA with important roles in cancer invasion and progression $(35,36)$.

In contrast to other cancers, such as prostate cancer, the combination of gene deletion and mutation status does not increase the malignant potential in esophageal cancer (22). In esophageal adenocarcinoma only 53 (21\%) patients showed TP53 deletion combined with strong p53 immunostaining, the rate being even lower in SCC with only $11 \%$. These low frequencies suggest that biallelic inactivation, which is associated with a total loss of functional p53, is a catastrophic cellular event related with a high level of apoptosis. Studies using transgenic mouse models carrying heterozygous TP53 deletions show larger and more mammalian tumors than animals with two wild type TP53 alleles (37). Moreover, the results from animal studies confirm the findings in our study, as these results indicate that loss of both TP53 alleles is not a prerequisite for tumor formation and that mere reduction in p53 levels may be sufficient to promote tumorigenesis.

Other studies have examined serum levels of p53 antibodies and their correlation to outcome. Shimada et al (38) reported on 28 patients with SCC that were positive for serum p53 antibodies out of a cohort of 105 cancers. These patients' survival was significantly worse than that of seronegative patients. To our knowledge, no correlation between serum p53 antibody levels and p53 expression in cancer tissue has yet been described for esophageal cancer. Our study does not provide any data on this issue since serum p53 antibodies were not examined in our cohort.

Seeing that cancers with strong p53 expression are correlated with poor survival independent of the established clinic-pathological prognostic markers supports the notion that these patients might profit from neoadjuvant and adjuvant therapeutic regimes in a multimodal setting. Tumor size, nodal 
status and resection margin appear to not be the only relevant markers for prediction of survival in EC and therefore the search for prognostic biomarkers is warranted even in this highly malignant disease with poor overall survival even in less advanced stages.

In summary, the results of our large-scale TMA analysis in esophageal adeno- and squamous cell carcinoma show that different types of $\mathrm{p} 53$ alterations characterize subgroups of patients with different outcomes. Strong p53 expression is correlated with unfavorable prognosis in esophageal cancer and represents an independent prognosticator in SCC. Furthermore, homozygous TP53 deletions are catastrophic cellular events related with a high level of apoptosis.

\section{Acknowledgements}

Not applicable.

\section{Funding}

No funding was received.

\section{Availability of data and materials}

The datasets used and/or analyzed during the current study are available from the corresponding author on reasonable request.

\section{Authors' contributions}

NM, SN, MK, RS and CHM conceived and designed the study, and acquired, analyzed and interpreted the data. SS, AH, EB, FJ, WW, AQ, MB, KG and MT were involved in drafting the manuscript, made substantial contributions to conception, analysis and interpretation of data and revised it critically for important intellectual content. JI, GS and FG made substantial contributions to study design, acquisition of data and gave final approval of the version to be published.

\section{Ethics approval and consent to participate}

Informed consent was not required due to the retrospective nature this study. Approval for manufacturing and analyzing tissue microarrays made from the tissue samples of anonymized donors was obtained from our local review board, the Ethics Commission of the Ärztekammer Hamburg (no. WF049/09).

\section{Patient consent for publication}

Not applicable.

\section{Competing interests}

The authors declare that they have no competing interests.

\section{References}

1. van Hagen P, Hulshof MC, van Lanschot JJ, Steyerberg EW, van Berge Henegouwen MI, Wijnhoven BP, Richel DJ, Nieuwenhuijzen GA, Hospers GA, Bonenkamp JJ, et al: Preoperative chemoradiotherapy for esophageal or junctional cancer. N Engl J Med 366: 2074-2084, 2012.
2. Siegel RL, Miller KD and Jemal A: Cancer statistics, 2015. CA Cancer J Clin 65: 5-29, 2015.

3. Rustgi AK and El-Serag HB: Esophageal carcinoma. N Engl J Med 371: 2499-2509, 2014.

4. Bian YS, Osterheld MC, Bosman FT, Benhattar J and Fontolliet C: p53 gene mutation and protein accumulation during neoplastic progression in Barrett's esophagus. Mod Pathol 14: 397-403, 2001

5. Kandoth C, McLellan MD, Vandin F, Ye K, Niu B, Lu C, Xie M, Zhang Q, McMichael JF, Wyczalkowski MA, et al: Mutational landscape and significance across 12 major cancer types. Nature 502: 333-339, 2013.

6. Dulak AM, Stojanov P, Peng S, Lawrence MS, Fox C, Stewart C, Bandla S, Imamura Y, Schumacher SE, Shefler E, et al: Exome and whole-genome sequencing of esophageal adenocarcinoma identifies recurrent driver events and mutational complexity. Nat Genet 45: 478-486, 2013.

7. Lin DC, Hao JJ, Nagata Y, Xu L, Shang L, Meng X, Sato Y, Okuno Y, Varela AM, Ding LW, et al: Genomic and molecular characterization of esophageal squamous cell carcinoma. Nat Genet 46: 467-473, 2014.

8. Wu C, Hu Z, He Z, Jia W, Wang F, Zhou Y, Liu Z, Zhan Q, Liu Y, Yu D, et al: Genome-wide association study identifies three new susceptibility loci for esophageal squamous-cell carcinoma in Chinese populations. Nat Genet 43: 679-684, 2011.

9. Muller PA and Vousden KH: p53 mutations in cancer. Nat Cell Biol 15: 2-8, 2013.

10. Huang K, Chen L, Zhang J, Wu Z, Lan L, Wang L, Lu B and Liu Y: Elevated p53 expression levels correlate with tumor progression and poor prognosis in patients exhibiting esophageal squamous cell carcinoma. Oncol Lett 8: 1441-1446, 2014.

11. Murata A, Baba Y, Watanabe M, Shigaki H, Miyake K, Karashima R, Imamura Y, Ida S, Ishimoto T, Iwagami S, et al: p53 immunohistochemical expression and patient prognosis in esophageal squamous cell carcinoma. Med Oncol 30: 728, 2013.

12. Yao W, Qin X, Qi B, Lu J, Guo L, Liu F, Liu S and Zhao B: Association of $\mathrm{p} 53$ expression with prognosis in patients with esophageal squamous cell carcinoma. Int J Clin Exp Pathol 7: 7158-7163, 2014.

13. Blanchard P, Quero L, Pacault V, Schlageter $\mathrm{MH}$, Baruch-Hennequin V and Hennequin C: Prognostic significance of anti-p53 and anti-KRas circulating antibodies in esophageal cancer patients treated with chemoradiotherapy. BMC Cancer 12: 119,2012

14. Chen M, Huang J, Zhu Z, Zhang J and Li K: Systematic review and meta-analysis of tumor biomarkers in predicting prognosis in esophageal cancer. BMC Cancer 13: 539, 2013.

15. Dey B, Raphael V, Khonglah Y and Lynrah KG: Immunohistochemical analysis of P53 and PRB in esophageal squamous cell carcinoma. J Clin Diagn Res 8: FC01-FC03, 2014.

16. Madani K, Zhao R, Lim HJ and Casson AG: Prognostic value of p53 mutations in oesophageal adenocarcinoma: Final results of a 15-year prospective study. Eur J Cardiothorac Surg 37: 1427-1432, 2010.

17. Pühringer-Oppermann F, Stahl M, Keller G and Sarbia M: Lack of prognostic impact of p53 gene mutation and p53 phosphorylation at serine 15 in multimodally treated adenocarcinomas of the gastroesophageal junction. J Cancer Res Clin Oncol 132: 433-438, 2006.

18. Wang ZB, Peng XZ, Chen SS, Ning FL, Du CJ, Wang K, Ma W and Cheng YF: High p53 and MAP1 light chain 3A co-expression predicts poor prognosis in patients with esophageal squamous cell carcinoma. Mol Med Rep 8: 41-46, 2013.

19. Xu XL, Zheng WH, Tao KY, Li XX, Xu WZ, Wang Y, Zhu SM and Mao WM: p53 is an independent prognostic factor in operable esophageal squamous cell carcinoma: A large-scale study with a long follow-up. Med Oncol 31: 257, 2014.

20. Niyaz M, Turghun A, Ping ZH, Zhu Z, Sheyhedin I, Ren C and Awut I: TP53 gene deletion in esophageal cancer tissues of patients and its clinical significance. Mol Med Rep 7: 122-126, 2013.

21. Mirlacher M and Simon R: Recipient block TMA technique. Methods Mol Biol 664: 37-44, 2010.

22. Kluth M, Harasimowicz S, Burkhardt L, Grupp K, Krohn A, Prien K, Gjoni J, Haß T, Galal R, Graefen M, et al: Clinical significance of different types of $\mathrm{p} 53$ gene alteration in surgically treated prostate cancer. Int J Cancer 135: 1369-1380, 2014. 
23. Krohn A, Diedler T, Burkhardt L, Mayer PS, De Silva C, Meyer-Kornblum M, Kötschau D, Tennstedt P, Huang J, Gerhäuser $\mathrm{C}$, et al: Genomic deletion of PTEN is associated with tumor progression and early PSA recurrence in ERG fusion-positive and fusion-negative prostate cancer. Am J Pathol 181: 401-412, 2012.

24. Song Y, Li L, Ou Y, Gao Z, Li E, Li X, Zhang W, Wang J, Xu L, Zhou Y, et al: Identification of genomic alterations in oesophageal squamous cell cancer. Nature 509: 91-95, 2014.

25. Shang L, Liu HJ, Hao JJ, Jiang YY, Shi F, Zhang Y, Cai Y, Xu X, Jia XM, Zhan QM and Wang MR: A panel of overexpressed proteins for prognosis in esophageal squamous cell carcinoma. PLoS One 9: e111045, 2014.

26. Saemi N, Khoshnevis J, Akbari ME, Meysamie A, Korourian A, Gholizadeh B, Larijani L, Moradi A, Baikpour M, Baikpour M and Zham H: Evaluating the correlation between the survival rate of patients with esophageal squamous cell carcinoma and expression of p53 and cyclin D1 biomarkers along with other prognostic factors. J Gastrointest Cancer 49: 35-40, 2018.

27. Wang L, Yu X, Li J, Zhang Z, Hou J and Li F: Prognostic significance of p53 expression in patients with esophageal cancer: A meta-analysis. BMC Cancer 16: 373, 2016.

28. Zhao Z, Wang P, Gao Y and He J: The high expression instead of mutation of p53 is predictive of overall survival in patients with esophageal squamous-cell carcinoma: A meta-analysis. Cancer Med 6: 54-66, 2017.

29. Muller PA and Vousden KH: Mutant p53 in cancer: New functions and therapeutic opportunities. Cancer Cell 25: 304-317, 2014.

30. Steurer S, Mayer PS, Adam M,Krohn A, Koop C, Ospina-Klinck D Tehrani AA, Simon R, Tennstedt P, Graefen M, et al: TMPRSS2-ERG fusions are strongly linked to young patient age in low-grade prostate cancer. Eur Urol 66: 978-981, 2014.

31. Sorsdahl K, Casson AG, Troster M, Van Meyel D, Inculet R and Chambers AF: p53 and ras gene expression in human esophageal cancer and Barrett's epithelium: A prospective study. Cancer Detect Prev 18: 179-185, 1994.
32. Leroy B, Fournier JL, Ishioka C, Monti P, Inga A, Fronza G and Soussi T: The TP53 website: An integrative resource centre for the TP53 mutation database and TP53 mutant analysis. Nucleic Acids Res 41 (Database Issue): D962-D969, 2013.

33. Brázdová M, Navrátilová L, Tichý V, Němcová K, Lexa M, Hrstka R, Pečinka P, Adámik M, Vojtesek B, Paleček E, et al: Preferential binding of hot spot mutant p53 proteins to supercoiled DNA in vitro and in cells. PLoS One 8: e59567, 2013.

34. Weisz L, Oren M and Rotter V: Transcription regulation by mutant p53. Oncogene 26: 2202-2211, 2007.

35. Dong P, Karaayvaz M, Jia N, Kaneuchi M, Hamada J, Watari H, Sudo S, Ju J and Sakuragi N: Mutant p53 gain-of-function induces epithelial-mesenchymal transition through modulation of the miR-130b-ZEB1 axis. Oncogene 32: 3286-3295, 2013.

36. Tucci P, Agostini M, Grespi F, Markert EK, Terrinoni A, Vousden KH, Muller PA, Dötsch V, Kehrloesser S, Sayan BS, et al: Loss of p63 and its microRNA-205 target results in enhanced cell migration and metastasis in prostate cancer. Proc Natl Acad Sci USA 109: 15312-15317, 2012.

37. Doyle B, Morton JP, Delaney DW, Ridgway RA, Wilkins JA and Sansom OJ: p53 mutation and loss have different effects on tumourigenesis in a novel mouse model of pleomorphic rhabdomyosarcoma. J Pathol 222: 129-137, 2010

38. Shimada H, Nabeya Y, Okazumi S, Matsubara H, Funami Y, Shiratori T, Hayashi H, Takeda A and Ochiai T: Prognostic significance of serum p53 antibody in patients with esophageal squamous cell carcinoma. Surgery 132: 41-47, 2002.

This work is licensed under a Creative Commons Attribution-NonCommercial-NoDerivatives 4.0 International (CC BY-NC-ND 4.0) License. 